\title{
Apresentação atípica de cancro do pulmão num doente jovem
}

Sofia Carvalho,* Liane Carreira**

\section{RESUMO}

O cancro do pulmão é a principal causa de morte por cancro nos homens. O diagnóstico pode ser tardio se a primeira apresentação for através de lesões atípicas.

Nódulos subcutâneos do couro cabeludo podem representar metástases de diferentes tumores. O carcinoma epidermóide do pulmão, embora raro, deve ser considerado quando essas lesões são encontradas. No caso apresentado, a evolução das lesões e a idade jovem do paciente sugeriram uma abordagem eficaz que levaou ao diagnóstico.

Palavras-chave: Cancro do Pulmão; Carcinoma Epidermóide; Metástases Cutâneas; Metástases do Couro Cabeludo.

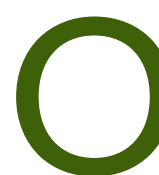

cancro do pulmão é a neoplasia mais frequentemente diagnosticada no mundo, apresentando-se como a causa de morte mais comum por cancro no sexo masculino e feminino.

Em Portugal, representa igualmente a principal causa de morte entre as neoplasias. A sobrevida global aos 5 anos é de cerca de $15 \% .{ }^{1}$ Dados recentes indicam uma incidência de $34 / 100000 \mathrm{com} 28 / 100000$ novos casos para o homem e 6/100 000 para a mulher. ${ }^{2}$

As manifestações iniciais de neoplasia pulmonar são muitas vezes heterogéneas e atípicas, o que se pode traduzir num diagnóstico tardio. As metástases cutâneas de neoplasia pulmonar representam uma manifestação rara, com incidência estimada de 1 a $12 \%,{ }^{4}$ e a sua ocorrência agrava o prognóstico da doença, traduzindo uma sobrevida média após diagnóstico entre 2,9 a 4,9 meses. Em 20 a $60 \%$ dos casos as metástases cutâneas podem revelar-se como manifestação clínica concomitante ou inicial de neoplasia pulmonar, ${ }^{4,9}$ sendo importante a valorização destas lesões na prática clínica, muitas vezes subdiagnosticadas.

*Assistente em Medicina Geral e Familiar; UCSP Tondela - Tondela.

**Interna do $3 .^{\circ}$ ano da especialidade de Medicina Geral e Familiar; USF Viriato Viseu.
Os quatro grupos histológicos de cancro de pulmão: carcinoma epidermóide, carcinoma pulmonar pequenas células (CPPC), adenocarcinoma e carcinoma de grandes células, representam $95 \%$ dos casos diagnosticados. O CPPC é considerado um subtipo histológico com características especiais que incluem um comportamento clínico agressivo com proliferação celular rápida, metastização precoce, associação frequente a síndromas paraneoplásicas, apresentação, à altura do diagnóstico, como doença quase sempre irressecável e maior sensibilidade à quimioterapia e radioterapia.

O caso clínico refere-se a um jovem, do sexo masculino, de 31 anos de idade, de raça caucasiana, natural e residente no concelho de Viseu.

O doente tinha história de alcoolismo, tabagismo (6 unidades maço - ano) e comportamento sexual de risco.

Não apresentava antecedentes familiares relevantes e apresentava como antecedentes patológicos conhecidos uma fractura traumática do pé esquerdo há cerca de um mês. Negava hábitos toxicológicos ou medicamentosos. Desconhecia contacto com doentes portadores de tuberculose pulmonar ou infecção por vírus da imunodeficiência humana (HIV).

Sem história ocupacional ou ambiental de risco. $\mathrm{O}$ doente negava contacto com animais ou viagens recentes. 
Recorreu à consulta programada da Unidade de Saúde Familiar (USF) por quadro com cerca de três meses de evolução de nódulos dolorosos do couro cabeludo e adenopatias dolorosas na região cervical acompanhado de anorexia, perda ponderal significativa $(10 \mathrm{~kg})$ e astenia. Negava febre, sudorese nocturna, fadiga, queixas respiratórias, gastrointestinais, urinárias e diátese hemorrágica.

Ao exame objectivo apresentava adenopatias cervicais bilaterais, de consistência mole, móveis e dolorosas à palpação, com a de maior diâmetro $(4 \mathrm{~cm})$ localizada na região cervical direita, não apresentava outras adenopatias e o exame da cavidade orofaríngea não revelou alterações. Apresentava nódulos subcutâneos, eritematosos, de consistência dura, vascularizados e dolorosos à palpação dispersos pelo couro cabeludo, com diâmetro máximo de cerca de $5 \mathrm{~cm}$ na região parieto-frontal esquerda (Figura 1). Relativamente a estes nódulos, o doente negou alteração do aspecto dos mesmos, nomeadamente na coloração, consistência, vascularização e temperatura, negando outras alterações tais como supuração. Não apresentava exantemas ou outras alterações cutâneas. O restante exame objectivo e o exame neurológico sumário era normal.

O doente foi encaminhado para o serviço de urgência do centro hospitalar de referência, tendo realizado os seguintes exames auxiliares de diagnóstico (EAD): análises que se revelaram normais; radiografia do tórax que mostrou alargamento moderado do mediastino superior; ecografia abdominal que foi normal e ecografia do pescoço que revelou «(...) na dependência da glândula submaxilar esquerda, formação nodular sólida heterogénea, de contornos irregulares, com 18,1 × 18,3 $\times$ $15,5 \mathrm{~mm}$ e nas cadeias ganglionares jugulo-carotídeas direitas, observaram-se múltiplas adenopatias; observou-se ainda trombose da veia jugular direita».

Perante a reunião de dados clínicos e anamnésicos as hipóteses de diagnóstico mais prováveis neste caso constituíram: infecção por HIV, tuberculose ganglionar, sarcoidose e doença neoplásica, nomeadamente linfoma cutâneo ou metastização carcinomatosa de tumor sólido.

O doente foi internado para estudo, tendo realizado EAD no sentido de excluir as hipóteses de diagnóstico mais prováveis referidas anteriormente (Quadro I). Foi realizada biópsia incisional do conglomerado adeno-

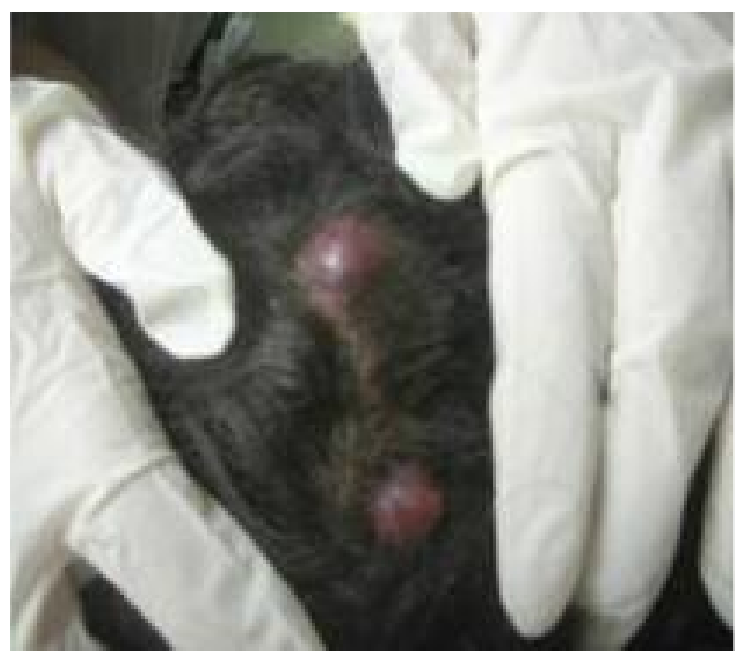

Figura 1. Nódulos subcutâneos localizados na região do couro cabeludo.

pático cervical e biópsia excisional de nódulo inflamatório do couro cabeludo, que revelou: «(...) metastização a nível cutâneo (couro cabeludo) e a nível ganglionar cervical de carcinoma pouco diferenciado, cujas características morfológicas e perfil imunohistoquímico põem como primeira hipótese tumor primitivo pulmonar».

Perante este resultado, foi efectuado o pedido de realização de tomografia computorizada (TC) toraco-abdomino-pélvica, a qual revelou: «Formação nodular com $2 \mathrm{~cm}$ de diâmetro de contornos espiculados e localização periférica no lobo inferior direito, muito suspeita de neoplasia pulmonar [Figura 2]; múltiplas massas adenopáticas no mediastino superior, posterior e hilo direito com marcada compressão a nível da veia cava superior».

Assim, considerou-se a realização de broncofibroscopia, com aspirado e lavado brônquico e biópsia aspirativa trans-torácica (BATT) do nódulo suspeito. A Broncofibroscopia revelou «(...) árvore brônquica esquerda com lesões nodulares da parede medial do brônquio principal esquerdo (BPE) sugestivas de lesões secundárias; RB1 com lesão vegetante e regular condicionando obstrução parcial do brônquio ramo superior direito», o aspirado brônquico revelou-se «Amicrobiano e negativo para células neoplásicas» e o escovado brônquico (realizado a nível do BPE) «(...) sugestivo de carcinoma pulmonar de não pequenas células 


\begin{tabular}{|c|c|}
\hline \multicolumn{2}{|c|}{$\begin{array}{l}\text { QUADRO I. Resultado dos exames complementares } \\
\text { realizados no Internamento. }\end{array}$} \\
\hline Serologias anti-HIV 1 e anti-HIV 2 & Negativas \\
\hline Estudo de subpopulações linfocitárias & Normal \\
\hline Título de anti-estreptolisina $O$ & Normal \\
\hline Hemograma & Normal \\
\hline Plaquetas & Normal \\
\hline Provas de função hepática & Normal \\
\hline Provas de função renal & Normal \\
\hline lonograma & Normal \\
\hline Tempo protrombina, TTPa e INR & Normal \\
\hline Velocidade de sedimentação & 59 \\
\hline Enzima conversora de angiotensina & Normal \\
\hline TSH, T3 livre e T4 livre & Normal \\
\hline Homocisteína & Negativo \\
\hline Proteína C & Negativo \\
\hline Proteína S & Negativo \\
\hline Anti-trombina III & Negativo \\
\hline Factor V Leiden & Negativo \\
\hline Mutação MTHFR & Negativo \\
\hline Anticorpos antinucleares & Negativo \\
\hline Antigénio nuclear extraível & Negativo \\
\hline Anti-DNA & Negativo \\
\hline Anti $\beta 2$-glicoproteína 1 & Negativo \\
\hline Anticorpos anti-cardiolipina & Negativo \\
\hline Anticoagulante lúpico & Negativo \\
\hline Proteinograma & Normal \\
\hline Doseamento imunoglobulinas & Normal \\
\hline Antigénio específico da próstata total & Normal \\
\hline Estudo bacteriológico da expectoração & $\begin{array}{l}\text { Negativo, inclusivé } \\
\text { para pesquisa de } \\
\text { bacilos ácido - } \\
\text { álcool resistentes }\end{array}$ \\
\hline
\end{tabular}

HIV: Vírus da imunodeficiência humana MTHFR: Metilenotetrahidrofolato redutase

TSH: Hormona estimulante da tiróide

T3: Triiodotironina

T4: Tiroxina

TTPa: Tempo de Tromboplastina Parcialmente ativada INR: International Normalized Ratio

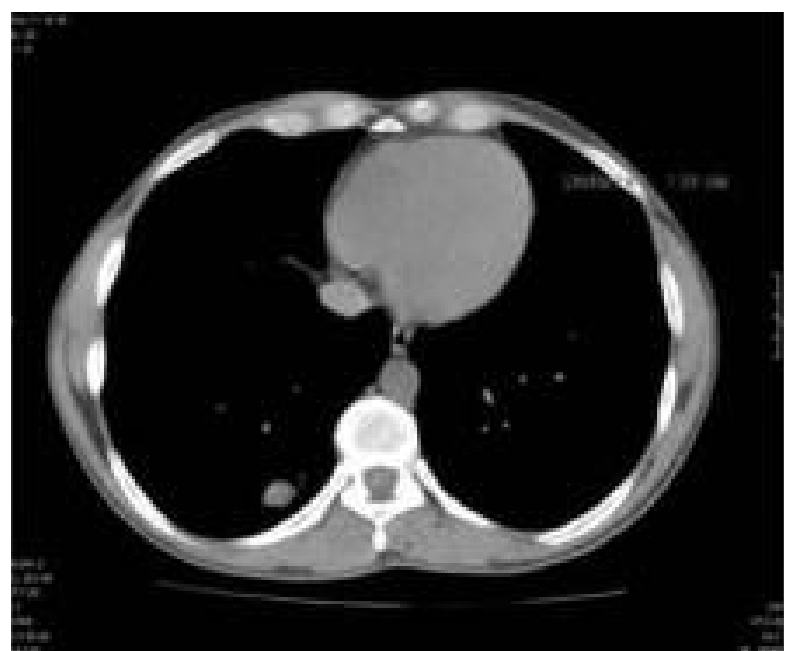

Figura 2. TC toraco-abdomino-pélvica: imagem nodular no lobo inferior direito suspeita de neoplasia pulmonar.

(CPNPC), provavelmente carcinoma epidermóide não queratinizado». A BATT revelou: «O estudo imunocitoquímico revelou positividade para a citoqueratina $7 \mathrm{e}$ negatividade para a citoqueratina 20 e TTF1. Estas características enquadram-se em carcinoma pouco diferenciado, de possível origem pulmonar, pancreática, vias biliares ou gástrica».

Como citado anteriormente, o doente apresentava história de fractura traumática do pé esquerdo (resultante de uma queda) sendo que, no contexto do diagnóstico de cancro do pulmão, revelou-se fundamental excluir fractura patológica. Deste modo, foi realizada radiografia do esqueleto com o seguinte relatório «(...) algumas lesões líticas na região proximal de ambos os fémures». De acordo com este resultado, e considerando que a metastização óssea é muito frequente em doentes com cancro em estadio avançado, nomeadamente no CPNPC, ${ }^{5}$ colocou-se como hipótese a metastização óssea das regiões proximais de ambos os fémures.

Ao $27 .^{\circ}$ dia de internamento, o doente inicia quadro súbito de confusão com agitação psicomotora, diplopia e ataxia da marcha, sem outros sinais ou sintomas acompanhantes. O doente realizou TC crânio-encefálica urgente, com o seguinte resultado «(...) cinco lesões nodulares encefálicas, compatíveis com metástases hemorrágicas, nomeadamente no hemisfério cerebeloso esquerdo, com efeito de massa no IV ventrículo (...) verifica-se hidrocefalia supra-tentorial devido à 
compressão do IV ventrículo [Figura 3]. Evidência de múltiplas metástases subcutâneas no couro cabeludo, uma com erosões associadas da calote craniana (região occipital direita) [Figura 4]». Instituiu-se terapêutica com dexametasona sem melhoria do quadro neurológico.

Foi também efectuado o pedido de marcadores tumorais para cancro do pulmão, nomeadamente Cyfra 21.1 e neuron-specific enolase, os quais se encontravam elevados: 44,2 $\mathrm{ng} / \mathrm{ml}$ (limite superior de 12,5 ng/ml) e $28,3 \mathrm{ng} / \mathrm{ml}$ (limite superior de 3,3 ng/ml), respectivamente. Estes valores predizem um pior prognóstico no CPNPC. ${ }^{6}$

Após a obtenção do diagnóstico de carcinoma pulmonar, foi exposto o caso clínico à Pneumologia, que estabeleceu contacto com a Oncologia Pneumológica do Centro Hospitalar de Coimbra, onde o doente foi observado para decisão terapêutica; no entanto consideraram que o doente não apresentava condições clínicas para iniciar quimioterapia ou radioterapia paliativas. Como tal, manteve terapêutica de suporte, nomeadamente tratamento da dor oncológica.

Verificou-se uma evolução clínica desfavorável, vindo o doente a falecer cinco semanas após a data de internamento.

\section{COMENTÁRIO}

As metástases cutâneas num carcinoma do pulmão primário são pouco frequentes, com uma incidência estimada inferior a $5 \% .^{7}$ As metástases do couro cabeludo são locais de metastização cutânea pouco frequentes nos tumores primários do pulmão; a publicação de escassos casos clínicos correlatos ${ }^{7-9}$ e a singularidade da idade jovem do doente do caso clínico apresentado ressalva a importância da sua discussão.

A maioria dos estudos revela ainda que o prognóstico global nos doentes com metástases cutâneas de neoplasia pulmonar primária é pobre, ${ }^{8}$ com uma sobrevida média inferior a 6 meses..$^{7-8} \mathrm{O}$ desfecho fatal deste caso clínico corrobora os dados actuais da literatura científica.

A presença de uma massa subcutânea em qualquer área da superfície corporal deve alertar o clínico para a possibilidade de uma neoplasia oculta, sendo que as manifestações inaugurais de carcinoma pulmonar deste caso clínico revelaram-se pertinentes como objecto

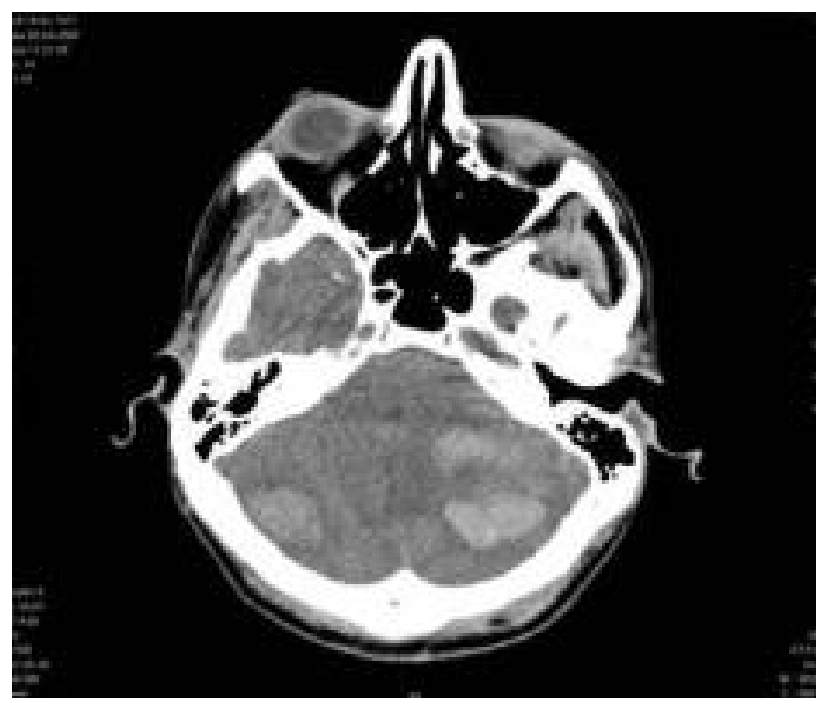

Figura 3. TC crânio-encefálica: metástases hemorrágicas cerebelares.

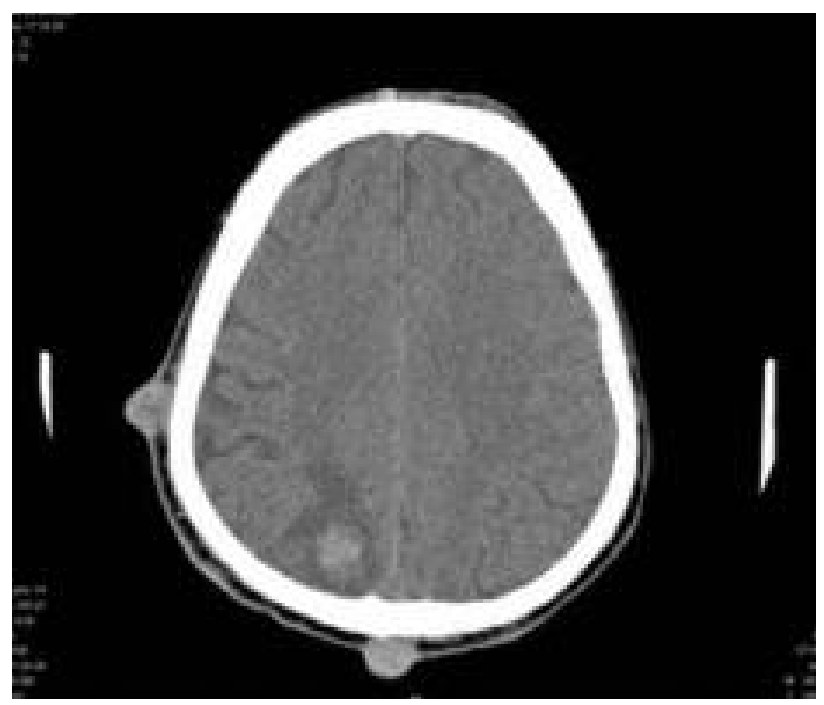

Figura 4. TC crânio-encefálica: metástases subcutâneas no couro cabeludo, uma com erosões associadas da calote craniana.

de discussão e reflexão.

O cancro do pulmão constitui um flagelo mundial, pelo que todas as estratégias preventivas e diagnósticas devem ser continuamente exploradas no sentido de debelar as perspectivas epidemiológicas naturalmente assustadoras. Tendo em conta o desfecho fatal do caso apresentado, torna-se imprescindível alertar para a necessidade de uma abordagem preventiva cada vez mais 
eficaz; o papel interventivo e precoce que o médico de família pode e deve ter na ajuda ao combate de hábitos nocivos, como o tabagismo, demarca a sua importância neste e em muitos outros casos.

O médico de família representa, na maioria das situações, o primeiro contacto do doente com o sistema de saúde, pelo que a sensibilidade diagnóstica e rapidez de orientação devem ser promulgadas com a apresentação de relatos semelhantes.

\section{REFERÊNCIAS BIBLIOGRÁFICAS}

1. Parente B, Queiroga H, Teixeira E, Sotto-Mayor R, Barata F, Sousa A, et al. Estudo epidemiológico do cancro do pulmão em Portugal nos anos de 2000/2002. Rev Port Pneumol 2007 Mar; 13 (2): 255-265.

2. Barata FJ, Costa AF. Carcinoma do pulmão de pequenas células: estado da arte e perspectivas futuras. Rev Port Pneumol. 2007 Jul; 13 (4): 587-604.

3. Sotto-Mayor R. Marcos históricos no estudo do cancro do pulmão. Rev Port Pneumol. 2006 Jul; 12 (4): 401-46.

4. Mollet TW, Garcia CA, Koester G. Skin metastases from lung cancer. Dermatol Online J 2009 May 15; 15 (5): 1.

5. Tsuya A, Kurata T, Tamura K, Fukuoka M. Skeletal metastases in nonsmall cell lung cancer: a retrospective study. Lung Cancer 2007 Aug; 57 (2): 229-32.
6. Barlési F, Gimenez C, Torre JP, Doddoli C, Mancini J, Greiller L, et al. Prognostic value of combination of Cyfra 21-1, CEA and NSE in patients with advanced non-small cell lung cancer. Respir Med 2004 Apr; 98 (4): 357-62.

7. Loh L-C, Raman S, Yusoff SM, Yaacob WA, Kumar S. Scalp metastasis from squamous cell carcinoma of lung. Grand Rounds 2005; 5: 19-21.

8. Patil C, Permi H. Scalp metastasis from squamous cell carcinoma of the lung. J Cancer Res Ther 2010 Jul-Sep; 6 (3): 402-3.

9. Gupta PP, Gupta KB, Gulia J, Agarwal D, Mehta D. Scalp lesion: a presenting feature of squamous cell carcinoma of lung. J Cancer Res Ther 2010 Jul-Sep; 6 (3): 370-3.

10. Terashima T, Kanazawa M. Lung cancer with skin metastasis. Chest 1994 Nov; 106 (5): 1448-50.

\section{CONFLITOS DE INTERESSE}

As autoras declaram não possuir qualquer tipo de conflito de interesses, financeiro ou outro.

\author{
ENDEREÇO PARA CORRESPONDÊNCIA \\ Ana Sofia Garcia de Carvalho \\ Av. Eng. ${ }^{\circ}$ Camilo Mendonça, Lote 12 \\ 5370-208 Mirandela \\ E-mail: anasofc@hotmail.com \\ Recebido em 12/01/2012 \\ Aceite para publicação em 05/11/2012
}

\section{ABSTRACT}

\section{ATYPICAL PRESENTATION OF LUNG CANCER IN A YOUNG PATIENT}

Lung cancer is the leading cause of death from cancer in men. The diagnosis may be delayed if atypical lesions are the first presentation. Subcutaneous nodules of the scalp may represent metastasis from various tumors. Small cell cancer of the lung, though rare, might be considered when lesions are found. In the case presented here, the evolution of the lesions and the young age of the patient suggested an effective approach that led to the diagnosis.

Keywords: Lung Cancer; Subcutaneous Nodules; Carcinoma; Squamous Cells; Metastasis. 